\title{
ABOUT SERENDIPITY INSIDE PROJECTS OR IMPROVE WHAT IS UNPREDICTABLE
}

\author{
Jean-Paul Bécar ${ }^{1}$, Jean Vareille ${ }^{2}$ \\ ${ }^{1}$ UPHF, LAMAV, CNRS 2956, IUT de Valenciennes, département GEll- Campus du Mont Houy - \\ 59313 VALENCIENNES \\ ${ }^{2}$ UBO, Lab-STICC UMR 6285, IUT de Brest-Morlaix, département GMP, CS 9383729238 BREST \\ CEDEX 3
}

\begin{abstract}
The paper deals with the serendipity emerging in projects. Serendipity means an unexpected and fortunate discovery. It happens mainly into projects thanks to the open mind behavior of stakeholders. Though two significant examples of project, the authors point out the moment where serendipity burst out. The authors are managing projects for twenty years and collaborating since over fifteen years. They are sharing, discussing and improving their own experience. After definition and some famous example of serendipity in centuries, two significant examples are proposed to the reader. They are concerned with students in second grade course in an Institute of Technology where projects are taking more and more time and space in their syllabus. The first subject deals with a concept car and the second talks about the regula falsi concept. The authors had recently the opportunity to propose a survey about serendipity to a group of a hundred of teachers-researchers. The results and comments end the paper.
\end{abstract}

Keywords: Serendipity, Innovation, Projects.

\section{INTRODUCTION}

The paper deals with the serendipity emerging in projects. As defined in their syllabus, the projects are concerned with students at the first, second or third grade in French Institutes of technology. The authors are working since decades in these Institutes. They are sharing their experiences, feedback and new experimentations for fifteen years. Although their research domains are different, they are always taking account of the new and running student's behaviour on sciences and technology. A recent discussion points out the unexpected scholarships.

In projects the open mind students relayed by their open mind teachers open the door to unexpected discovery that is defining the serendipity. Last centuries gave some examples as the Archimedean buoyant force, the Gutenberg printing press or the radioactivity. The serendipity comes from nowhere, it cannot be mastered. It cannot be taught. But, a new environment and an open mind behaviour ease the serendipity access. This is given in section two.

In section three two examples follow. The first one deals with the concept car project. At its starts, a project was managed by a group of students interested in the 3D digitizer based on a cheap and efficient device. The second example talks over the Regula Falsi method also called as the guess and check or trial and error method. Taught in USA as a general problem solving method in the K12 scholar curriculum, in the European countries it is taught in numerical analysis only in the Universities.

Pushing the classroom walls, giving time to time, opening his mind, learning with sharing are elements of the serendipity that must reveal the students talent and free their creativity.

The authors had recently the opportunity to propose a survey about serendipity to a group of a hundred of teachers-researchers. The results and comments end the paper.

\section{THE SERENDIPITY}

Serendipity means an unexpected and fortunate discovery [1][2]. The Cholera vaccine, Archimedes upward buoyant force, Lascaux caves discovery, Gutenberg printing press or the radioactivity are some famous examples of serendipity. These discoveries sharpen the creativity and provide inventions or innovation sometimes. As examples of this fruitful process we cite few well known. The 
tiny and strong hooks in the burs of the cocklebur flowering plant built the Velcro brand. Viagra was initially applied for the chest pain treatment. New recipies has been founded by fortune as the French tarte Tatin apple pie or the bêtises de Cambrai candy.

The serendipity affects the creativity according to 3 approaches:

Expansion: The serendipity is opening the mind to new unexpected results.

Ratification: The serendipity is becoming a new concept or a new action plan.

Innovation: The serendipity is suggesting changes in action plan, interpretation and overview.

The serendipity comes from nowhere. It can't be taught. It can't master. However, it can be spurred. An adequate environment prepares its coming [3] [4]. Observing and having an open mind are the basics of serendipity.

What are the reasons when something unexpected is discovered? The following gives some answer elements.

Team working and sharing information,

Travelling,

Meeting and talking with unknowns,

Participating to an event in a unknown place,

Looking at the causes and effects of something observed but not yet explained.

What are the principles to spur the serendipity?

Be aware,

Change the point of view on the regular place of work, change the furniture location,

Adapt yourself to unknown places, tools, persons with their own and different culture,

Always take note and date of what is happening, what are the sensations.

In that kind of environment, a wide area is devoted to share information, knowledge or know-how. The Fablab system, the multimedia library or associations workshop give opportunity for serendipity. In France the recent laboratory of innovation called the 110bis feeds this dynamics [5].

Louis Pasteur said that the unexpected observations can only profit to a well prepared spirits.

\section{TWO SIGNIFICANT EXAMPLES}

In order to illustrate the previous theoretical situation described above, 2 significant examples are proposed to the reader. The first is concerned with a concept car spread other a three years projects and the second deals with the Regula Falsi rule generally applied in mathematics but here experimented as a way to make students more sensitive to what do or what they can imagine. In both projects, the stakeholders are becoming more confident. The students are doing more unforced efforts and their guides too as half a way has been run. The first sub-part of the section reminds readers about the structure of the French institute of technology.

\subsection{The Institute of Technologies}

The creation of Institute of Technologies in France was decided on sixties. The aim was to provide French companies with qualified employees specialized in fast developing technologies to bring help to engineers and companies in their efforts to modernization. The creation of Institutes of Technology was also a part of the territorial management. As Universities are only located in bigger towns, the creation of Institute of Technology in medium-sized cities is an opportunity to bring new technologies everywhere in the country to help local companies. It is also an opportunity to bring more young people to new jobs, in particular people from families with low income, who could not afford studies in bigger and more expansive towns. The Institute of Technology is one answer. (http://www.iutenligne.net/). The domain taught are directly in connection with companies activities. The Institute of technology delivers a University Diploma of Technology -DUT in French-. The diploma 
indicates a level of theoretical and practical skills in order to get a legal superior technician salary. The course takes two years after their baccalaureate. Some students are going on for a one year specialization in a bachelor of technology course. The best of them are changing their career path while going on in an engineer school.

According to their academic syllabus and in order to foster initiative, a large part of course is devoted to projects. The projects represent about ten percent of the final marks for the diploma validation after two years courses in theoretical, technical domains and its applications. The objectives for teachers are to make students more sensitive to the mixed knowledge, to manage a group rather giving academic lessons. In any case, one success element of the project is laying on two facts always checked. First, the students define themselves the project to be completed. Such a behaviour can be found in the purchase decision discussed by J. Dewey one hundred years ago meaning that good ideas are out of age $[1,2]$. Second the availability of the teacher manager feeds the wheel of constant improvement.

The running technology makes any syllabus difficult to match with it in a short delay. For future technicians, if the theoretical lessons are unavoidable, they must know what is new in their domain. A free pedagogical space is offered by projects.

\subsection{The concept car project}

The specialty in that is concerned with the electrical engineering domain including elements of electronics, electrotechnics, control process, automation and local area network. For the project, the subject is mainly concerned with the mechanical domain. It tries to prove that the can-do attitude will drive the project to its end. The essential performance can be found in the consumer behavior modelled by John Dewey[6].

The project has been launched in the area of a 3D digitizer based on a 3D video games equipment. A group of four students proposed to apply the 3D digitizer. One hour weekly briefing is located in the electrical engineering workshop. This open place for safety reasons, eases the moving of persons and also unformal meeting and discussion. During one weekly briefing discussion some students talked about one of their friend fond of cars drawing. While showing its cars to the group, another student took the initiative to model the cars in a software. The concept car project was thus launched. It includes the car design, its 3D printing out, a wooden rapid prototyping and a thermoforming shape. The students in electrical engineering domain open their mind and their teacher too to the mechanical design process. [ref].

It took 3 years to be ended. Many parameters take part in the success. The choice of subject by the student and its validation by the teacher according to local equipment hardware as software, the students willing to realize something they designed, the open space of the workshop, the fixed meeting a week, the no classroom working place, the availability of the teacher.

The steps of the concept car projects are shown in Figure 1.
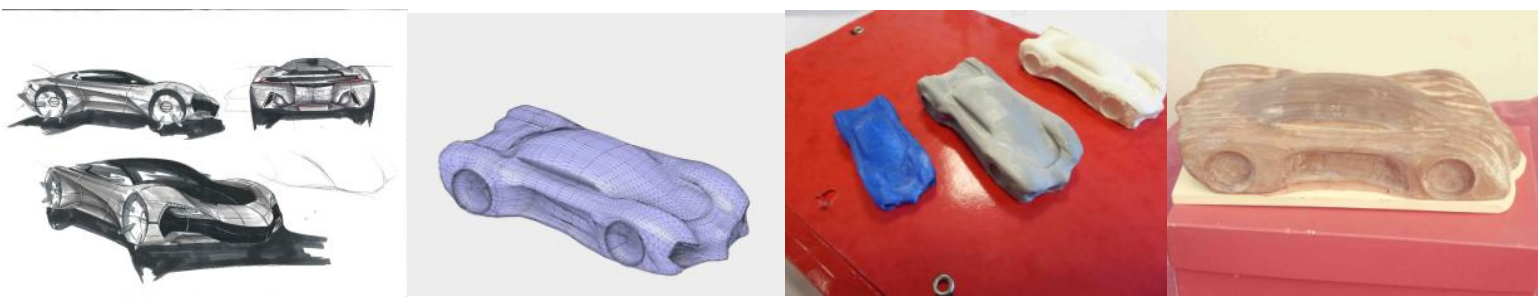

Figure 1. The concept car project, from left to right: sketch, virtual model, 3 printed out, wooden rapid prototype

\subsection{The Regula Falsi experience.}

One author, a teacher-researcher in mechanics, discovered it in a book written by Johannes Widmann in 1489 about the pretty computations of merchants[8].. He was first searching if the + sign was a - sign crossed out. The starting idea was coming from the system engineering, when we add something to a system we subtract the corresponding quantity to the environment. The choice of the sign - or + depends only of the point of view. The old book was the first one where the + and - signs 
appeared. The given explanations confirmed the idea. Reading further the book the author discovered the Regula Falsi. He composed a sheet of exercises related to his teaching. He tried it in his classrooms composed of mechanical engineering students. Without any previous knowledge about the trial and error method, up to fifteen per cent of students are able to apply it. Through this unexpected cursus it appears that it is possible to start a research from a funny idea, and step after step, amazing results could be obtained inducing further researches.

This author also wrote a method for problem solving. The Regula Falsi method is taught in Europe in numerical analysis. In the USA this cross disciplinary method is used in the K12 academics context. It is named "guess and check " or "trial and error " method [10]. The trial and error method states the founding principles of the mechanics reasoning. One author of the paper is a teacher-researcher in Mechanics, teaching at an Institute of Technology. He wrote a text including two exercises, a question of barrel and taps and another on a field and mowers, and proposed it to a group of students. It results that $15 \%$ have solved the first exercise and $5 \%$ the second without former awareness on the trial and error method. This serendipity example has been applied in a teaching experience giving an unexpected result.

At a yearly conference for all Institute of Technology, the authors had the opportunity to ask their colleagues on the serendipity subject. They propose a questionnaire detailed and commented forward.

\section{A SURVEY}

\subsection{The list of questions}

The questions have been available on a website for the hundred of stakeholders. About fifteen percent of colleagues answered. The list of question follows.

\begin{tabular}{|l|l|l|l|}
\hline 1 & Do you know what is the serendipity? & Y & $N$ \\
\hline
\end{tabular}

In case of Yes, do you have any experience:

\begin{tabular}{|l|l|c|l|}
\hline 2 & Before this conference & $\mathrm{Y}$ & $\mathrm{N}$ \\
\hline 3 & In your own or social life & $\mathrm{Y}$ & $\mathrm{N}$ \\
\hline 4 & In your professional life & $\mathrm{Y}$ & $\mathrm{N}$ \\
\hline 5 & In a project & $\mathrm{Y}$ & $\mathrm{N}$ \\
\hline 6 & In the preparation of a lesson or a talk & $\mathrm{Y}$ & $\mathrm{N}$ \\
\hline
\end{tabular}

7 During the conference, did you meet a situation of serendipity?

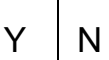

In case of yes, that was during :

\begin{tabular}{|l|l|c|c|}
\hline 8 & a talk session & $\mathrm{Y}$ & $\mathrm{N}$ \\
\hline 9 & a poster session & $\mathrm{Y}$ & $\mathrm{N}$ \\
\hline 10 & the conference dinner & $\mathrm{Y}$ & $\mathrm{N}$ \\
\hline 11 & others (bus, taxi, train, breakfast, lunch) & & \\
\hline
\end{tabular}

Is a situation of serendipity important for:

12 A new direction of your research? 


\begin{tabular}{|l|l|l|l|}
\hline 13 & Your own life? & Y & N \\
\hline
\end{tabular}

\begin{tabular}{|l|l|l|l|}
\hline 14 & $\begin{array}{l}\text { Does a serendipity situation in your professional life could influence your } \\
\text { research? }\end{array}$ & $\mathrm{Y}$ & $\mathrm{N}$ \\
\hline 15 & $\begin{array}{l}\text { Conversely, does a serendipity situation in your research could influence your } \\
\text { professional life? }\end{array}$ & $\mathrm{Y}$ & $\mathrm{N}$ \\
\hline
\end{tabular}

\subsection{Results and comments}

$50 \%$ of the audience knows what serendipity is. Among this group, many of them have experienced the serendipity situation in their professional life $(90 \%)$ or projects $(80 \%)$. During the conference over $70 \%$ have experienced the serendipity mainly in unformal context as lunches or trips.

About $30 \%$ of colleagues think that the serendipity is important for new direction of research or own life. But in case of a serendipity situation makes a great influence on research and professional life.

\subsection{Discussion}

As the serendipity is adding value to any project, it can be stimulated by the principles described above. Gathering all elements that are seeds of an unexpected discovery. Writing down what is new and can be attached to the present project otherwise what can be used later. That kind of elements should be written for further project. The note book contains three parts. One personal, the second private and the third public as it is suggested by the experimental notebook from the French organism la main à la pâte [11]. This last is applied in secondary school with stimulation on scientific observations as the main objective.

Here the goal consists in technological innovation within projects. The personal part should include in addition of new ideas some emotion elements happening while creating. The private part contains the informations shared with the working group eventually reported in a laboratory handbook in case of writing a patent[12]. The third and public part contains everything to be shared using webpage, a common space to share with students or the entire Institute, even more. Moreover, some companies are using the idea box [13] with a web access as Motivation Factory (www.motivationfactory.com). Thus, the serendipity can be intentional [14].

Before the internet, the social network and the mutual influence played a role in innovation and invention[15]. The last author points out that the founder is not a loner working alone.

\section{CONCLUSION}

The last conference where authors had the opportunity to participate provides a framework to share information, know-how, new ideas and experiences. The authors guess that the serendipity will be grown in the future. The unexpected discovery should open the doors to a new teaching world based on the open mind mainly.

\section{ACKNOWLEDGEMENTS}

The authors would like to warmly thank the University of Valenciennes UPHF and the Institute of Technology IUT and the University of Brest UBO and the Institute of Technology IUT for offering the working environment and in particular the availability of all technical staff. 


\section{REFERENCES}

[1] Cristophoro Armeno, "Viaggi e avventure dei tre principi di Serendippo»; Michele Tramezzino, Venise Editor, 1557. Traduit en français par Louis de Mailly, édition de MDCCLXXXVIII, book diffused in Great-Britain, the word serendipity was created by Horace Walpole 4th Earl of Oxford.

[2] Office québécois de la langue française, "Grand Dictionnaire », fiche terminologique sur la sérendipité,

[3] Stephann Makri, "Accidental information discovery, cultivating serendipity in the digital age ", Tammera m. Race, ,Elsevier Chandos publishing, 2016.

[4] Mickaël Gallais, "La sérendipité : présentation, typologie, applications et rôle en sciences de l'information et en documentation », mémoire DUT Septembre Bordeaux, 2007.

[5] Ministère de l'éducation nationale et de la jeunesse, "Le 110bis, lab d'innovation de l'éducation nationale ", Paris, 2018.

[6] John Dewey, "How we think", D.C, Heath and CO. Publishers, 1910.

[7] Denis Guedj, « Le théorème du perroquet », Éditions du Seuil, coll., Points, novell, Paris, 1998.

[8] Johannes Widmann, "Behende und hübsche Rechnung auff allen Kauffmannshafften » printed by Conrad Kacheloffen, 236 folios, Leipzig, 1489. (The Augsbourg'edition of 1526 is on-line,

[9] Jérôme Gavin, Alain Schärlig, « Longtemps avant l'algèbre : la fausse position ; ou comment on a posé le faux pour connaître le vrai, des Pharaons aux temps modernes », Presses polytechniques et universitaires romandes, Lausanne, 224 p., 2010.

[10] Christopher Glavin, " Problem solving 》, K12 Academics, 2004-2019.

[11] La main à la pâte, “Qu'est ce que le cahier d'expériences », 2001.

[12] Réseau Curie, " cahier de laboratoire national », 2007.

[13] Corinne Moriou, «Comment réinventer la boîte à idées dans l'entreprise ». l'Express l'Entreprise, 2013. dans-I-entreprise_1523939.html

[14] Jean-Yves Garnier, « la Sérendipité intentionnelle 》.

[15] Francis C. Moon, "Social Networks in the History of Innovation and Invention", Springer verlag, 2013.x 